IZA DP No. 4793

Strategic Behavior across Gender: A Comparison of Female and Male Expert Chess Players

Christer Gerdes

Patrik Gränsmark

February 2010 


\title{
Strategic Behavior across Gender: A Comparison of Female and Male Expert Chess Players
}

\author{
Christer Gerdes \\ SOFI, Stockholm University \\ and IZA \\ Patrik Gränsmark \\ SOFI, Stockholm University
}

\author{
Discussion Paper No. 4793 \\ February 2010
}

\author{
IZA \\ P.O. Box 7240 \\ 53072 Bonn \\ Germany \\ Phone: +49-228-3894-0 \\ Fax: +49-228-3894-180 \\ E-mail: iza@iza.org
}

Any opinions expressed here are those of the author(s) and not those of IZA. Research published in this series may include views on policy, but the institute itself takes no institutional policy positions.

The Institute for the Study of Labor (IZA) in Bonn is a local and virtual international research center and a place of communication between science, politics and business. IZA is an independent nonprofit organization supported by Deutsche Post Foundation. The center is associated with the University of Bonn and offers a stimulating research environment through its international network, workshops and conferences, data service, project support, research visits and doctoral program. IZA engages in (i) original and internationally competitive research in all fields of labor economics, (ii) development of policy concepts, and (iii) dissemination of research results and concepts to the interested public.

IZA Discussion Papers often represent preliminary work and are circulated to encourage discussion. Citation of such a paper should account for its provisional character. A revised version may be available directly from the author. 
IZA Discussion Paper No. 4793

February 2010

\section{ABSTRACT \\ Strategic Behavior across Gender: A Comparison of Female and Male Expert Chess Players ${ }^{*}$}

This paper aims to measure differences in risk behavior among expert chess players. The study employs a panel data set on international chess with 1.4 million games recorded over a period of 11 years. The structure of the data set allows us to use individual fixed-effect estimations to control for aspects such as innate ability as well as other characteristics of the players. Most notably, the data contains an objective measure of individual playing strength, the so-called Elo rating. In line with previous research, we find that women are more riskaverse than men. A novel finding is that males choose more aggressive strategies when playing against female opponents even though such strategies reduce their winning probability.

JEL Classification: J16, J70, J71, D03

Keywords: risk aversion, competitiveness, gender, culture, mixed-sex competition

Corresponding author:

Christer Gerdes

Swedish Institute for Social Research

Stockholm University

SE 10691 Stockholm

Sweden

E-mail: Christer.Gerdes@sofi.su.se

\footnotetext{
* The authors would like to thank Anders Stenberg, Eskil Wadensjö, participants at the SOFI seminar, the ESPE conference in Seville and the EALE conference in Tallinn, for comments on earlier drafts of the paper. Special thanks to Fredrik Stark for excellent data assistance and the makers of ChessBase, who kindly allowed us to use their data.
} 


\section{Introduction}

In a number of areas the underrepresentation of women is a striking reality. This applies to top positions in politics, public and government administration, the academic professions, and not least corporate management. Such diverse outcomes have been observed even in markedly equality-aware societies such as the Swedish; see Albrecht et al. (2003), Booth (2007), Jonung and Ståhlberg (2008), and references therein. As noted by Booth (2007), economists have only recently tried to amend the standard human-capital model that seeks to explain gender differences in incomes and promotion by taking into account aspects such as culture, bargaining skills and tastes or preferences. ${ }^{1}$ If it is the case that men, on average, are more competitive and less risk-averse than women, this might in part explain why promotion to higher positions has been advantageous for male candidates. Indeed, a number of studies provide evidence of systematic gender differences in terms of risk behavior and competitiveness. One issue still open for debate is whether these are innate differences or not, i.e. whether observed differences across gender in terms of risk taking and competitiveness are biologically or socially determined. ${ }^{2}$

\footnotetext{
${ }^{1}$ For example, Bowles, Gintis and Osborne (2001), point at the importance of non-cognitive skills as determinants for earnings. See also Bas ter Weel (2008) on the importance of noncognitive skills for predicting labor market outcomes.

${ }^{2}$ On the importance of the position of women in society for competitive behavior see Gneezy et al (2009). In a field study of the Khasi tribe in India and the Maasai tribe in Tanzania, they found that in a society organized along matrilineal lines, like the Khasi tribe, women chose competitive schemes more often than the men in their tribe. The authors take their result as evidence of the impact of social learning on behavior, but they also point at the fact that cultural choice may alter genetic evolution through various selection mechanisms.
} 
Our aim in this paper is threefold: First, we examine whether there are general gender differences in risk behavior. Second, as chess is a game between two players, it is possible to analyze the interactive risk behavior of a man playing against a woman compared to when he plays against a man and vice versa. This aspect relates to research on the importance of the composition of a group, i.e. whether individuals act differently in single-sex or mixed groups; see Gneezy et al. (2003) and Booth (2009) for a discussion on possible explanations for various outcomes found in the literature. Third, we investigate whether the behavior we have studied is rational or not in terms of winning probabilities.

The study relates to recent studies that have tried to test the supposition of differences across gender with respect to risk taking and competitiveness. ${ }^{3}$ Much of the literature has focused on experimental evidence, for example by looking at children or students competing under controlled conditions. Our study adds to that literature by providing evidence from a non-experimental setting, using comprehensive records of games played by a great number of top-level chess players. There are few other studies that have focused on differences in risk behavior and competitiveness outside the laboratory environment. For example, Bajtelsmit and Barnasek (1996) look at real world investment decisions for non-professional investors, while Olsen and Cox (2001) look at professional female and male investors. As stressed in Bajtelsmit and Barnasek (1996), differences across gender in financial placement strategies might be caused by the fact that the access to information varies in quality, where men might systematically receive "better" advice/information than their female counterparts. This could

\footnotetext{
${ }^{3}$ See Booth (2009) and Croson and Gneezy (2009) for a survey and references on the issue of differences in risk preferences and competitiveness across gender in experimental studies. A related aspect addressed in the literature on gender differences regards overconfidence; see e.g. Bengtsson et al. (2005), Datta Gupta et al. (2005), and Nekby et al. (2008). Sometimes the three concepts are used interchangeably, indicating that they overlap to a certain extent.
} 
be due to male networks, but also to discriminatory treatment. None of these studies addresses the importance of mixed-sex competition.

As has been noted by several scholars within the field of cognitive sciences, there is a common set of skills appropriate for people working in advanced areas of the business world and academia, as well as for top-level chess. This holds not least because successes in these areas are associated with intelligence and expertise (see Bilalić et al. 2007, p. 460), as will be discussed in more detail below. Moreover, since chess is a game between two players, it definitely constitutes a (highly) competitive setting, thereby reflecting the nature of what is the daily routine for many actors in the corporate world and the field of government, as well as in academia. Becoming an expert chess player is by no means an easy task. Those who attain the higher ranks are certainly more competitive than people in general. This may apply to a greater extent to female players, i.e. they are presumably more competitive than women in general. The latter supposition is based on experimental evidence showing that women are less prone to choose tournaments than men (see e.g. Niederle and Vesterlund, 2007). Thus, in our study we look at preferences for risk across gender for a selected group of competitive people. Our results point at significant differences in risk taking across gender. Most notably, both men and women seem to change strategy when they face a female opponent.

In section 2 we argue why research on chess data is a suitable complement to earlier research on (non-)cognitive differences across gender. Section 3 provides a short theoretical background to our estimation approach, while section 4 presents the data. In section 5 we present and discuss the results of our estimations, while section 6 concludes the study. 


\section{Why study chess?}

This section aims to emphasize that findings based on chess can be transferred to other professions that are characterized by a high level of expertise. It thereby highlights the importance of having an accurate measure of a person's skill level, the so-called Elo rating.

For a number of years, strategic aspects involved in playing the game of chess have become an established analytical tool in cognitive psychology. In his review of the literature, Roring (2008) describes what makes chess a constructive method for the analysis of different aspects of human behavior: "Finding the best move in a chess position is a highly complex, real-world human activity, and each chess position represents a well-defined problem environment, with a fixed number of identifiable moves that can be played at any given point - perfect for studying search processes and problem solving" (p. 1).

A landmark for establishing chess as an analytical tool was the introduction of the Elo rating that made it possible to compare the strength of chess players on a metric scale. Named after its inventor, Arpad Elo, it has become the benchmark classification in chess.

[It] provides chess researchers with a valid measurement device unrivalled in other areas of expertise research. It is a true gold standard in individual-difference research. /.../ Other frequently investigated areas such as physics expertise $/ . . . /$ do not permit such fine differentiation (Charness 1992, p. 6).

Thus, with reference to Elo (1978), it has become possible to measure skills on objective grounds, i.e. there are no "subjective assessments" (Chabris and Glickman 2006, p. 1040). ${ }^{4}$ Also, as argued by different scholars in the field, e.g. Gobet (2005), Ross (2006) or

\footnotetext{
${ }^{4}$ The Elo rating system is calculated using an algorithm based on the assumption of a normal distribution of playing strength across chess players. See the Appendix for a detailed description on how Elo points are estimated.
} 
Roring (2008), chess is well-suited to address questions concerning cognitive and psychological processes, thus extending its relevance to various fields of research studying human behavior. For example, one result obtained from chess research is that it takes about ten years of intense learning and hard work to become an expert, a time frame that also fits with "arts, sports, science, and the professions" (Gobet 2005, p. 185). ${ }^{5}$

Anecdotal evidence maintains that there is a positive correlation between skills in chess and intellectual capacity. Indeed, some research points at the legitimacy of such views; see for example Frydman and Lynn (1992). Other studies that have looked at the correlation between chess rating and intellectual capability have not provided support for this supposition; see Waters et al. (2002). As they argue, conflicting conclusions might be due to the fact that the groups that are scrutinized differ to some extent with respect to their demographic composition. In particular, Frydman and Lynn (1992) study children, while Waters et al. (2002) look at adult chess players. As argued by Waters et al. (2002), the importance of innate intellectual capacity will fade as children mature and learn to compensate for their weaknesses through purposeful training, resulting in approved chess skills and higher Elo ratings. One influential paper in the field of cognitive research arguing along these lines is Ericsson et al. (1993). It proposes the concept of "deliberate practice," which denotes a person's commitment to persistently exercise laborious tasks. The authors see such a trait as a vital

\footnotetext{
${ }^{5}$ There are only few studies in economic literature that study chess players. In Ariga et al. (2008), a player's Elo rating is studied as a signal for talent and as advice to invest in becoming a (professional) chess player. Another study, by Moel and Nye (2009), looks at (illegitimate) cooperation among expert players. A third study is by Levitt et al. (2009), who let top-level chess players solve different games designed for testing their backward induction skills. Their study responds to Palacios-Huerta and Volij (2009), who use a similar experimental setup.
} 
ingredient in attaining extraordinary (chess) skills. Thus, in their view, it is the capacity to direct one's attention to monotonous, repetitive tasks over a long period of time, which is decisive for the attainment of specialist knowledge, rather than innate aptitude. Recent studies suggest that advanced chess skills are the result of innate personal characteristics, as well as persistent practicing, see Gobet and Campitelli (2007) and Grabner et al. (2007).

In the world of chess, information on strategic concerns is accessible to everyone, especially since the Internet has become commonplace in daily life. Moreover, the signal of a player's strength, i.e. the Elo rating, is of a similar quality irrespective of gender. In other words any incentive to invest in chess skills will not be distorted by one's expectations of becoming a victim of (statistical) discrimination. ${ }^{6}$ Due to the lack of "old boys' networks" or "gatekeepers to high positions" in chess (Chabris and Glickman, 2006), this will allow us to elucidate some genuine gender differences on risk decision-making. ${ }^{7}$

\section{Theoretical framework}

To obtain our measure of risk behavior we exploit the fact that chess players start each game by choosing a strategic development scheme for their pieces (called a chess opening). By exploiting a standardized classification of these openings, we can label the chosen strategies in each game as being either risky (aggressive) or safe (solid).

\footnotetext{
${ }^{6}$ The prevalence of diverse incentives to invest in human capital following from different prospects of signaling skill and expertise in a statistical discrimination framework has been addressed in numerous studies; see Bjerk (2008) and references given there.

${ }^{7}$ Chabris and Glickman (2006), similar as Bilalić et al. (2009), refute the assertion made by Howard (2005) who reads the lack of top-level female chess players as evidence for gender differences in intellectual capacity.
} 
We use aggressiveness and solidity as our key concepts, meaning that a solid player is considered a risk-averse person, and an aggressive player is a risk-loving person. An aggressive playing tactic always involves a higher level of risk, as launching an attack on one part of the board implies that you neglect another. Typically, in such positions every move tends to be of utmost importance. Solid play avoids many possible weaknesses but at the cost of fewer attacking possibilities. Usually, one slip in a solid position will not lose the game.

A chess game is divided into three parts, the opening, the middlegame and the endgame. The opening moves are "theoretical" and are memorized before the game, and, since no calculation is needed, these moves are played quickly. The opening theory covers most reasonable moves by the opponent and usually includes somewhere between ten and twenty moves in depth for each variation.

In the opening, a player opts to have an answer to every reasonable move by the opponent. This very quickly becomes a great deal of theory to memorize, and to cut down on the theoretical preparation, a chess player limits his/her opening variation to include as few openings as possible (some deliberate variation is maintained to reduce predictability). A player's set of openings is called an opening repertoire (OR). Considerable effort is dedicated to creating an opening repertoire that matches one's personality. A player with temperament will typically choose more aggressive openings, while a calm, "peaceful" person will more often choose a solid opening. Since opening preparation requires a lot of hard work, the main body of the opening repertoire is kept for a long time, usually for years. As a player develops, the opening repertoire will undergo changes, but the basis usually remains the same.

In a game theoretical framework chess is a sequential game where the players make moves in turn, as shown in the following game tree. We show one opening to exemplify the grounds on which it can be regarded as aggressive or solid. 


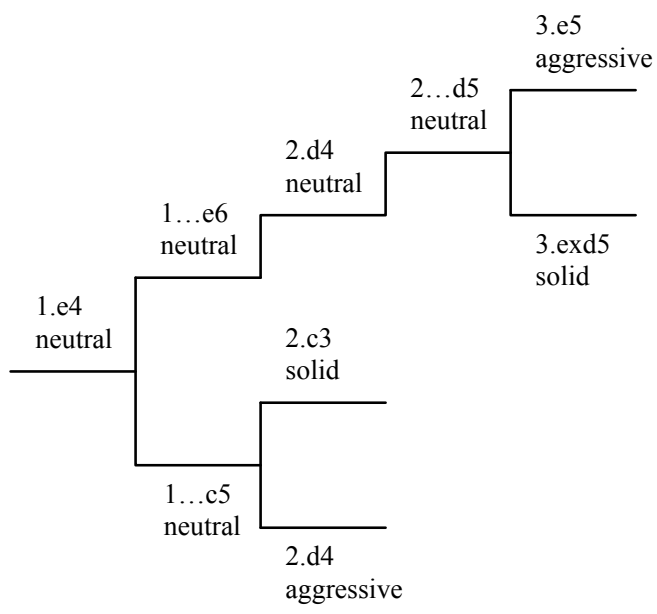

After the first move for each side (1.e4 and $1 \ldots$ e6/1...c5), it is too early to classify the opening as being solid or aggressive. ${ }^{8}$ In the second and third moves, however, it is often possible to choose a move that leads to an aggressive or solid position, respectively. In the first end-node of the game tree, white grabs space with 3.e5, which will be used for an attack later on. In the second end-node, 3.exd5, white chooses a symmetric position without space advantage but avoiding weaknesses. In the third end-node, 2.c3, white chooses a more quiet system, but in the fourth, 2.d4, a pawn is sacrificed to assure initiative and attack.

There are thousands of books on opening theory, recommending openings for different styles, so there is a great deal of knowledge about the strategic nature of the openings among chess players. A classification of openings, called Eco codes, with 500 opening categories has been in use for the last fifty years. We have consulted eight chess experts of different strengths with Elo rates ranging from 2000 to 2600, five men and three women, and have

\footnotetext{
${ }^{8}$ To ease notation, the game tree only shows the possible strategies from the perspective of the player of the white pieces. Also, for the sake of simplicity, only pawn moves are discussed here. The annotation "1...e6" should be understood as: "the first move (1.) for black (...) and a pawn is moved to the coordinate e6." In "exd5" x reads as "takes on."
} 
asked them to give their opinion on the character of all the Eco codes. ${ }^{9}$ In more detail, they were instructed to define each opening as either aggressive or solid. We then compare the opinions of the experts and declare an Eco code to be solid [aggressive] if at least six out of eight experts define it as solid [aggressive]. ${ }^{10}$ In cases when there are five or fewer votes for either solid or aggressive, the opening is considered to be unclear. About 1 percent of the games lack Eco codes and are excluded from the estimations; i.e. they enter into the category "A00," which has become a residual of non-classified openings.

As a result of our experts' assessments, there are two labels for each game, one for the player of the white pieces and one for the black. This means that white can open solidly while black chooses a more aggressive approach. In such a case the label is " $\mathrm{S}$ " for white and "A"

${ }^{9}$ According to the International Chess Federation (FIDE), a player is regarded as an expert if he/she has an Elo rating of 2000 or more. The lowest level required to obtain a Master title is a rating of 2300. A Grandmaster title usually implies an Elo rating of over 2500. In the year 1999 Garry Kasparov reached an Elo rating of 2851, the highest Elo rating ever measured.

${ }^{10}$ See the Appendix for the instructions given to the experts and an extract from the questionnaires they filled out. The time each expert spent on the classifications varied between two and five hours. Each expert was unaware of the opinions of the other experts. In an earlier version of this paper we used the expertise of just four of our experts, two men and two women. The classification on openings differs slightly, but overall this does not affect the outcomes very much; see Gerdes and Gränsmark (2009) on estimation results based on the previous classification. To test the reliability of our procedure, we also tested a "five out of eight experts" requirement rule. Overall the outcomes are similar; however, in some estimations the results become more distinct. Nevertheless, we stick to the "six of eight experts" requirement rule, among others to guarantee that at least one woman is part of the decisive majority. 
for black. Consequently, there are four different possibilities for each Eco code: "AA", "AS", "SA" and "SS." See the Appendix for descriptives on the classification of openings.

\subsection{Econometric model}

In the estimations each game in our data is treated as one observation. We start by showing results on gender differences as regards the probability of choosing a solid [aggressive] opening strategy or not. In general, estimations with a binary dependent variable can be done in various ways. To facilitate interpretation, we have chosen to focus on OLS estimations in a "linear probability model" (LPM) framework. The equation we estimate looks as follows:

$$
\mathrm{y}_{i j}=\alpha_{i j}+\beta \mathrm{x}_{i j}+\mathbf{w}_{i j} \pi+e_{i j}
$$

where $\mathrm{y}$ is the dependent variable of playing solid [aggressive] and $x$ is a gender dummy which takes on the value one if the player observed (index $i$ ) in a game (index $j$ ) is a woman, zero if a man, $\mathbf{w}$ is a vector of control variables (discussed below), while $e$ denotes the standard error. The coefficient $\beta$ states the difference across gender as to the propensity to choose a solid [aggressive] strategy. A positive [negative] $\beta$ would point at women being more risk-averse than men, and vice versa.

Our set of control variables is motivated by the following aspects. The share of female chess players has been growing in later years. Since most new chess players appearing in the top ranks of international chess are fairly young, it follows that women are on average younger than men. Also, women may to a certain extent drop out when they reach childrearing age. For this reason it is important to include control variables for age to pick up such 
patterns. ${ }^{11}$ A control for Elo ratings is used to hold constant for systematic differences in chess skills across gender. We also include a control for the number of games recorded for a player in a given year, which is meant to account for the strength in the signal of risk preferences. $^{12}$

Subsequent estimations aim at examining the importance of the gender of the opponent for the decision on what strategy to choose. There we include additional controls: individual fixed-effects, the strategy chosen by the opponent, as well as the Elo points that can be won or lost in a game. These estimations are made separately for male and female players. In those estimations the variable of interest is thus defined as playing against a female player.

\section{Data and statistics}

The data in this study were taken from ChessBase 10, a commercial database collection with 3.8 million chess games played in international chess events. It contains about 200,000 players from all over the world. The data are organized in two dimensions, player-specific information and game-specific information. The name, year of birth, nationality and gender of a player are available. For every game there is data on the names and current Elo ratings of both players, the year a game was played, number of moves, Eco codes and the score, i.e. if a game was won, lost or ended in a draw. Before the beginning of the 1990s, such information

\footnotetext{
${ }^{11}$ Besides linear and quadratic age variables, we include a dummy for "age $0-20$ " to allow for different intercepts and to account for the fact that teenagers are often considered to be more aggressive and impatient due to high levels of sex and growth hormones, see Kimura (1996). 12 Organizers of chess events report the results (including a complete move sheet) immediately after the event. Information on chess players' records are updated several times a year. Before a game, a player is informed about the name and playing strength of the opponent and can easily look up his or her playing history via the Internet.
} 
was coded by hand. With the arrival of digital storage facilities, data processing became the standard procedure, leading to a substantial increase in the number of games reported. Since 1997 the registration of players and games played has become smoother across events and countries and for this reason we have limited our study to include games played from 1997 to 2007. To assure a certain level of chess expertise we only include players with a minimum Elo rating of 2000. A player at this level is considered to be a chess expert and we assume that he/she has established his/her opening repertoire. ${ }^{13}$ After imposing these restrictions, our sample includes ca 15 thousand players and 1.4 million games.

Mean values are shown in Table 1. Regarding the information on a player's nationality, we have grouped the countries in regions based on geographical lines and chess popularity. The regions with the highest number of chess players are Western Europe, Eastern Europe and the former Soviet Union. These three regions account for about 90 percent of the expert chess players in the world. Western Europe alone accounts for 45 percent, Eastern Europe for 27 percent and the former Soviet Union for about 18 percent, see panel A. Latin America, North America, Africa and Asia account for about 10 percent. Women have about a hundred points lower Elo rating points than men when averaged over the whole sample. The female share varies considerably across regions, as can be seen in panel $\mathrm{B}$, from just over 5 percent in Western Europe, to 10 percent in Eastern Europe, and to 15 percent in the former Soviet Union.

\section{Table 1 about here}

\footnotetext{
${ }^{13}$ To be more exact, we require that at least one of the two players in each game fulfills the lower bound of 2000 in Elo. Furthermore, only players that have a record of at least twenty games between 1997 and 2007 are included in our sample, this to assure variation in the choice of a player's strategy.
} 
The female share among top players has been rising constantly in the last two decades; consequently women are on average younger than male chess players. The average male player is 34 years old while the average female player is 25 . In the former Soviet Union the mean age is much lower and the difference between the sexes is not as great as in Western Europe. ${ }^{14}$ The female share decreases as we move up the Elo ladder, as can be seen in Figure 1 in the next section. At Elo rate 2000, the female share is 17 percent, while at the very top (Elo 2600-2851) the female share is only about 1 percent.

It should be pointed out that the number of internationally registered chess players differs considerably across regions. It is also likely that some less-developed countries only register higher-rated players, which might explain why countries with relatively few registered players have a rather high Elo average. The chess rating system in the USA is somewhat different from the definition applied by the International Chess Federation (FIDE). The data in ChessBase 10 are based on the definition made by FIDE and, consequently, only a few US players are included in the dataset.

\section{Estimation results}

In Table 2, the results from the OLS estimations are shown. As can be seen from column (1), the female dummy coefficient is .0204, implying that the marginal probability for women to choose a solid opening strategy is about 2 percentage points greater than for men, holding constant for age, Elo rating, number of games played and regional dummies. The estimate is significant on a one-percent level, which implies that there is strong statistical support for the claim that female players prefer opening strategies that are considered more risk-averse than their male counterparts. In column (2) we show the outcome of regression estimations where we use our measure of aggressive OR as dependent variable. The solid and

\footnotetext{
${ }^{14}$ Information on gender differences across regions is available on request.
} 
the aggressive OR are close but not perfect reflections of each other, as some openings have been left uncategorized (i.e. they did not fulfill the "at least six out of eight experts" requirement). ${ }^{15}$ The female dummy coefficient is both negative and significant, which is consistent with the positive results found for solid OR as a dependent variable. ${ }^{16}$ The marginal effect is estimated at -.0197 , i.e. women have a 2 percentage point lower probability of choosing an aggressive opening than male players, after controlling for other covariates.

\section{Table 2 about here}

In order to understand how the female coefficient is affected at different levels of playing strength, we also run separate regressions for eleven intervals with a range of 50 Elo points each. The female dummy coefficients for the solid OR are positive over all intervals (except one), see Figure 1.

\section{Figure 1 about here}

As we turn to aggressive OR in Figure 2, it reveals a mirror image of Figure 1. The results appear to be even stronger as the female coefficients are consistently below zero and the standard errors notably smaller. It is worth pointing out that the consistently negative coefficient estimates are paralleled by a substantial decrease in the share of females. This means that differences with respect to taste for risk are more or less stable, irrespective of the actual level of skill of the players or the female share within each interval.

\section{Figure 2 about here}

\footnotetext{
${ }^{15}$ As can be seen in Table 1 , about 47 percent of the played openings are considered to be solid, 20 percent aggressive according to their classification.

${ }^{16} \mathrm{We}$ also run probit estimations; the results are similar to the OLS estimates.
} 


\subsection{Impact of mixed-sex competition}

As a result of the detailed information given in our data set it is also possible to take into account certain characteristics of the opponent in each game played. This allows us to look at gender-affected strategies, i.e. the issue of whether the choice of strategy depends on the sex of the opponent or not. In Table 3 we show the results from regression estimations that aim to test whether male players change their strategy when facing a female opponent. Correspondingly, in Table 4 we present the results from the perspective of a female player.

For male players the probability of choosing a solid strategy is about 1.3 percent lower when facing a female opponent compared to a male opponent, see column (1) in Table 3 . In other words, men on average abstain more often from using solid strategies when playing against women. Apart from our standard set of control variables, three additional controls are included consecutively: individual fixed effects, the opponent plays a solid strategy and Elo points at stake. The first set of control variables is intended to hold constant for all kinds of time-persistent characteristics of players. The second addresses the fact that women choose solid openings to a greater extent (as we saw previously), which might per se trigger a player to respond by playing a (non-)solid strategy. The third control variable picks up the marginal amount of Elo points a player can gain by winning that game. It is based on accounts of the difference in Elo ratings between both players. ${ }^{17}$ As one can see in columns (2) and (3), these additional controls do not change the fact that men, when playing against women, are less inclined to play solid. We also compare the choice of strategy of players when they face an opponent with a lower or higher Elo rating respectively, see columns (4) and (5). The estimate in column (5) shows a slight indication that also weaker players, in terms of their Elo rating, are more likely to refrain from using solid openings when they play against women.

\footnotetext{
${ }^{17}$ See the Appendix for information on how this variable is constructed.
} 


\section{Table 3 about here}

The pattern for female players is quite different; see Table 4 . The coefficients are much smaller and overall insignificant. Our interpretation of this is that women are not affected by the sex of their opponent when it comes to choosing whether to play a solid strategy or not.

\section{Table 4 about here}

Looking at aggressive OR instead of solid OR as the outcome variable leads to similar outcomes, at least as regards male players. The coefficient estimates point at men choosing more aggressive strategies when facing a female opponent, see Table 5. Interestingly, the estimate in column (5) shows that in cases where men are on objective grounds weaker players than their female opponents, their propensity to opt for an aggressive opening strategy seems to become even greater. ${ }^{18}$

\section{Table 5 about here}

Turning to female players shown in Table 6, we see a clear difference as regards aggressive OR compared to the estimated relations in estimations looking at solid $\mathrm{OR}$ in Table 4. When women are playing against female players, they show a greater inclination to use an aggressive strategy compared to when playing against a man, see column (3). Looking at columns (4) and (5) it becomes evident that the effect is driven by the outcomes from a setting where women meet female opponents with higher Elo ratings than themselves.

\footnotetext{
${ }^{18}$ The difference in coefficient estimates in columns (4) and (5) is not significant. However, when we use a classification of openings applying a "five of eight experts" requirement, the coefficient estimates indicate a significantly greater propensity to use aggressive opening strategies against females if a man is a weaker player.
} 
The results highlight the marginal importance of single-sex vs. mixed-sex competition as regards the choice of (aggressive) strategy. In particular, on the margin both men and women condition their choice on the sex of their opponent. Our findings are to some extent consistent with those reported in Maass et al. (2008). Their results show that female players were less prone to announce an "aggressive intent" when they were told they were facing a male opponent. ${ }^{19}$

\section{Table 6 about here}

\subsection{Rational, yes or no?}

Why do male chess players choose to refrain from playing a solid game and opt for more aggressive strategies when they play against female opponents? Could it be rational to pursue a more aggressive strategy? In an attempt to find an answer, we investigate whether men have a greater winning probability when they use such a strategy in games where they face a female opponent. For a strategy to be seen as rational, we simply require that it should result in a higher probability of winning a game. For analytical clarity, it is desirable to use an unambiguous outcome measure, so here we only consider wins and losses, not draws. The results of estimations are shown in Table 7 where the outcome of the game (a win is coded as 1, a loss as 0 ) has been regressed on choosing a solid strategy, holding constant for other aspects, similar to the earlier regressions. We find that when a man plays against a woman, a solid strategy has a 1.5 percentage point higher probability of winning compared to not using

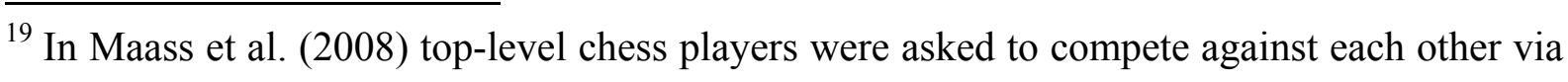
a computer platform, so no participant had any personal contact with his/her opponent. They argue that their findings can be explained by gender stereotyping that would depress women's self-confidence.
} 
such strategy. ${ }^{20}$ Our interpretation of these results is that, on average, it does appear irrational for males to opt for less solid strategies when they face a female opponent.

\section{Table 7 about here}

\subsection{Discussion of results}

We have looked at different outcomes aimed at measuring strategic behavior. We have found that women choose more cautious strategies than men, which we interpret as women being more risk-averse on average. As this study provides a new way of studying risk behavior, it is not obvious how to relate the size of the measured effects to other findings in the literature. At first sight, the estimates may not seem very great. However, this does not mean that the effects are negligible. Remember that the estimates state the average gender differences for one game; the number of games played in FIDE approved tournaments and other events over a one-year period is about 34 for men and 33 for women, see Table 1 . This implies that the impact of differences in the choice of strategies on a player's prospect of advancing in his/her career might cumulate over time. ${ }^{21}$ In addition, the measured effect is

${ }^{20}$ Looking at the outcome of playing aggressive OR for the propensity to win against a female opponent generates consistent results, i.e. lower winning probabilities. For women the results are comparable, i.e. less solid/more aggressive play against a female opponent results in a lower propensity to win against a female opponent. Estimates are more distinct for women, i.e. both greater and overall significantly different from zero. Results are available on request from the authors.

${ }^{21}$ See Eagly (1995) for a discussion on the (difficult) issue of interpreting the real impact of measured statistics in the context of behavioral research, especially as regards gender differences. 
important because it turns out to be pervasive, i.e. it even holds when we restrict estimations to comprise the world's best-performing chess players, as can be seen in Figure $2{ }^{22}$

A rather novel result in this study regards the fact that men choose to refrain from using solid strategies, as well as becoming more prone to using aggressive strategies, when facing a female opponent. In some models estimated, women too behave more aggressively against their female peers by choosing a more aggressive strategy. ${ }^{23}$ It is striking that both men and women seem more inclined to choose a risky strategy when facing a female opponent on occasions when the opponent is superior by means of their respective Elo ratings. We are not in a position to provide a conclusive explanation for the latter result; however, some theories on stereotyping within the social psychological literature fit in nicely with our results. According to these studies "judgment can become more stereotypic under cognitive load," (Macrae and Bodenhausen 2000, p. 105). Under the assumption that the "cognitive load" becomes greater when playing against a stronger player, gender stereotyping could be used as a "cognitive shortcut," i.e. used as a means of processing information in a heuristic mode. As Hilton and von Hippel (1996) report, stereotyping can manifest itself through the selective judgment of evidence, for example regarding another person's intelligence. Thus, stereotyping seems to be a plausible explanation for our findings, especially as we find the elevated aggressiveness against women not to be rewarding, i.e. irrational in economic terms.

\footnotetext{
${ }^{22}$ The latter result is in contrast to studies referred to in Croson and Gneezy (2009), saying that gender differences among managers and entrepreneurs in risk taking attenuate with experience and profession.

${ }^{23}$ This is in line with the findings by Holm (1996) who showed that both men and women behaved more aggressively against women.
} 


\section{Concluding comments}

In our introduction we sought to establish a link between the strategic thinking of highly skilled chess players on the one hand, and the chances of successfully climbing the career ladder on the other. There are innumerous situations where men and women compete, for example in a negotiating situation, which might be characterized as a "two-person competition," as noted by Niederle and Vesterlund (2007). They show that compared to men women avoid competitive schemes, and when forced to compete, they fail to do so appropriately. Basically, our results are consistent with theirs; however, we add a new facet by showing that men become more inclined to choose aggressive strategies when they face a female opponent. One might read this result in terms of overconfidence. Some studies point at men being more overconfident than women, especially in "male-dominated realms" such as trading, see Barber and Odean (2001). Based on our results, male overconfidence might become even stronger when men face a female opponent. Alternatively one might read the results in terms of gender stereotyping, leading to the undervaluation of the real capacity of women in cognitive demanding situations. The latter aspect might also explain why women too are more prone to choosing aggressive (i.e. risky) strategies when playing against female opponents who on objective grounds are stronger players.

One objection that might be raised against this study is that it focuses on a nonrepresentative selection of people, i.e. a group more accustomed to complex strategic thinking than people in general. Also, as the female share among chess players is low it is possible that the motivation that drives women to playing chess is different from the motivation that drives men. Both aspects suggest that one should be careful not to generalize the results too far. On the other hand, by using a large panel data set, we are in a position to control for individual heterogeneity by means of including individual fixed-effects. In combination with the Elo rating, which permits controlling for differences in skills (i.e. 
productivity), this study adds a new dimension to the existing research on risk behavior. Furthermore, as our sample of chess players comprises people from (almost) all over the world, the behavioral patterns found are not tied to a specific cultural, religious or social environment. Rather, they reflect expressions of human interaction that people share irrespective of heritage.

The fact that we can observe mixed-group behavior in a competitive environment is a main contribution of the paper. It thereby emphasizes the importance of interpersonally determined mechanisms occurring in highly competitive situations. In particular, our results shed a new light on the discussion on what determines differences between men and women in intellectually demanding professions. We believe that different outcomes across gender are not merely a question of deliberate discrimination on the part of men, but are at least to some extent due to deep-rooted mechanisms that surface in situations where competitors of the opposite sex meet. Naturally, our results should be tested and validated in other settings. If they stand up to comprehensive examination, they will certainly become important for designing policy measures aimed at counteracting the disadvantaged position of women in different parts of society.

\section{References}

Albrecht, J., Björklund, A., Vroman, S., 2003. Is There a Glass Ceiling in Sweden?. Journal of Labor Economics 21, 145-177.

Ariga, K., Brunello, G., Iwahashi, R., Rocco, L., 2008. The Stairways to Heaven: A Model of Career Choice in Sports and Games, with an Application to Chess, IZA Discussion Paper No. 3327.

Bajtelsmit, V. L., Bernasek, A., 1996. Why Do Women Invest Differently than Men?. Financial Counseling and Planning 7, 1-10. 
Barber, B. M., Odean, T., 2001. Boys Will Be Boys: Gender, Overconfidence, and Common Stock Investment. Quarterly Journal of Economics 116, 261-292.

Bengtsson, C., Persson, M., \& Willenhag, P., 2005. Gender and Overconfidence. Economic Letters 86, 199-203.

Bilalić, M., McLeod, P., Gobet, F., 2007. Does Chess Need Intelligence? - A Study with Young Chess Players. Intelligence 35, 457-470.

Bilalić, M., Smallbone, K., McLeod, P., Gobet, F., 2009. Why are (the best) Women so Good at Chess? Participation Rates and Gender Differences in Intellectual Domains. Proceeding of the Royal Society B: Biological Sciences 276, 1161-1165.

Bjerk, D., 2008. Glass Ceilings or Sticky Floors? Statistical Discrimination in a Dynamic Model of Hiring and Promotion. Economic Journal 118, 961-982.

Booth, A. L., 2007. The Glass Ceiling in Europe: Why are Women Doing Badly in the Labour Market?, Swedish Economic Policy Review 14, 121-144.

Booth, A. L., 2009. Gender and Competition. Labour Economics 16, 599-606.

Bowles, S., Gintis, H., Osborne, M., 2001. The Determinants of Earnings: A Behavioral Approach. Journal of Economic Literature 39, 1137-1176.

Chabris, C. F., Glickman, M. E., 2006. Sex Differences in Intellectual Performance Analysis of a Large Cohort of Competitive Chess Players. Psychological Science 17, $1040-1046$.

Charness, N., 1992. The Impact of Chess Research on Cognitive Science. Psychological Research 54, 4-9.

Charness, N, Tuffiash, M., Krampe, R., Reingold, E., Vasyukova, E., 2005. The Role of Deliberate Practice in Chess Expertise. Applied Cognitive Psychology 19, 151-165.

Croson, R., Gneezy, U., 2009. Gender Differences in Preferences. Journal of Economic Literature $47,448-474$. 
Datta Gupta, N., Poulsen, A., Villeval, M.-C., 2005. Male and Female Competitive Behaviour: Experimental Evidence, IZA Discussion Paper No. 1833.

Eagly, A. H., 1995. The Science and Politics of Comparing Women and Men. American Psychologist 50, 145-158.

Elo, A. E., 1978. The Rating of Chessplayers, Past and Present (London: Batsford).

Ericsson, A. K., Krampe, R. Th., Tesch-Romer, C., 1993. The Role of Deliberate Practice in the Acquisition of Expert Performance. Psychological Review 100, 363-406.

Frydman, M., Lynn, R., 1992. The General Intelligence and Spatial Abilities of Gifted Young Belgian Chess Players. British Journal of Psychology 83, 233-235.

Gerdes, C., Gränsmark, P., 2009. Strategic Behavior across Gender: A Comparison of Female and Male Expert Chess Players. Paper presented at the EALE conference 2009, http://www.eale.nl/Conference2009/Programme/PapersB/add101739_zSWVHEMqRe.pdf.

Gneezy, U., Niederle, M., Rustichini, A., 2003. Performance in Competitive Environments: Gender Differences. Quarterly Journal of Economics 118, 1049-1074.

Gneezy, U., Leonard, L. K., List J. A., 2009. Gender Differences in Competition: Evidence from a Matrilineal and Patriarchal Society. Econometrica 77, 1637-1664.

Gobet, F., 2005. Chunking Models of Expertise: Implications for Education. Applied Cognitive Psychology 19, 183-204.

Gobet, F., Campitelli, G., 2007. The Role of Domain-specific Practice, Handedness and Starting Age in Chess. Developmental Psychology 43, 159-172.

Grabner, R. H., Stern, E., Neubauer, A. C., 2007. Individual Differences in Chess Expertise: A Psychometric Investigation. Acta Psychologica 124, 398-420.

Hilton, J. L., von Hippel, W., 1996. Stereotypes, Annual Review of Psychology 47, 237-271. Holm, H. J., 1998. Gender-based Focal Points. Games and Economic Behavior 32, 292-314. 
Howard, R. W., 2005. Are Gender Differences in High Achievement Disappearing? A Test in one Intellectual Domain. Journal of Biosocial Science 27, 371-380.

Jonung, Ch., Ståhlberg, A.-Cha., 2008. Reaching the Top? On Gender Balance in the Economic Profession. Economic Journal Watch 5, 174-192.

Kimura, D., 1996. Sex, Sexual Orientation and Sex Hormones Influence Human Cognitive Function. Current Opinion in Neurobiology 6, 259-263.

Levitt, S., List, J., Sadoff, S., 2009. Checkmate: Exploring Backward Induction Among Chess Players. NBER Working Paper Series, http://www.nber.org/papers/w15610

Maass, A., D'Ettole, C., Cadinu, M., 2008. Checkmate? The role of gender stereotypes in the ultimate intellectual sport. European Journal of Social Psychology 38, 231-245.

Macrae, C. N., Bodenhausen, G. V., 2000. Social Cognition: Thinking Categorically about Others. Annual Review of Pscyhology 51, 93-120.

Moul, C. C., Nye, J. V.C., 2009. Did the Soviets collude? A statistical analysis of championship chess 1940-1978. Journal of Economic Behavior \& Organization 70, 10 21.

Nekby, L., Skogman-Thoursie, P., Vahtrik, L., 2008. Gender and Self-Selection Into a Competitive Environment: Are Women More Overconfident Than Men?. Economics Letters 100, 405-407.

Niederle, M., Vesterlund, L., 2007. Do Women Shy Away from Competition? Do Men Compete Too Much?. Quarterly Journal of Economics 122, 1067-1101.

Olsen, R. A., Cox, C. M., 2001. The Influence of Gender on the Perception and Response to Investment Risk: The Case of Professional Investors. Journal of Psychology \& Financial Markets 2, 29-36.

Palacios-Huerta, I., Volij, O., 2009. Field Centipedes. American Economic Review 99, 16191635. 
Roring III, R. W., 2008. Reviewing Expert Chess Performance: A Production Based Theory of Chess Skill, Dissertation Department of Psychology, Florida State University.

Ross, P. E., 2006. The Expert Mind. Scientific American 295, 64-71.

Ter Weel, B., 2008. The Noncognitive Determinants of Labor Market and Behavioral Outcomes: Introduction to the Symposium. Journal of Human Resources 43, 729-737.

Waters, A. J., Gobet, F., Leyden, V., 2002. Visuospatial Abilities of Chess Players. British Journal of Psychology 93, 557-565.

\section{Appendix}

\section{Expert enquiry: Instructions to the chess experts}

For every Eco code you must decide whether the opening is to be considered as aggressive, solid, or unclear. Denote your definitions using A, S or 0 respectively. This should be done from the perspectives of both players (white and black). As most Eco codes contain subopenings where some can be aggressive and others solid within the same Eco code, you should focus on what you believe is the principal opening and that is played most frequently. The key moves are those where the players must decide on the character of the game, i.e. "am I to choose the safe path or the risky path?". It is your feeling or belief about the opening that is important, not "the philosophical truth" from a theoretical perspective that is still to be discovered. Try to use the same information as you would when you choose what openings to include in your (opening) repertoire. You will be compensated for a maximum of five working hours.

Table A.1

Classification of standard opening by expert chess players

Extract from the questionnaire 


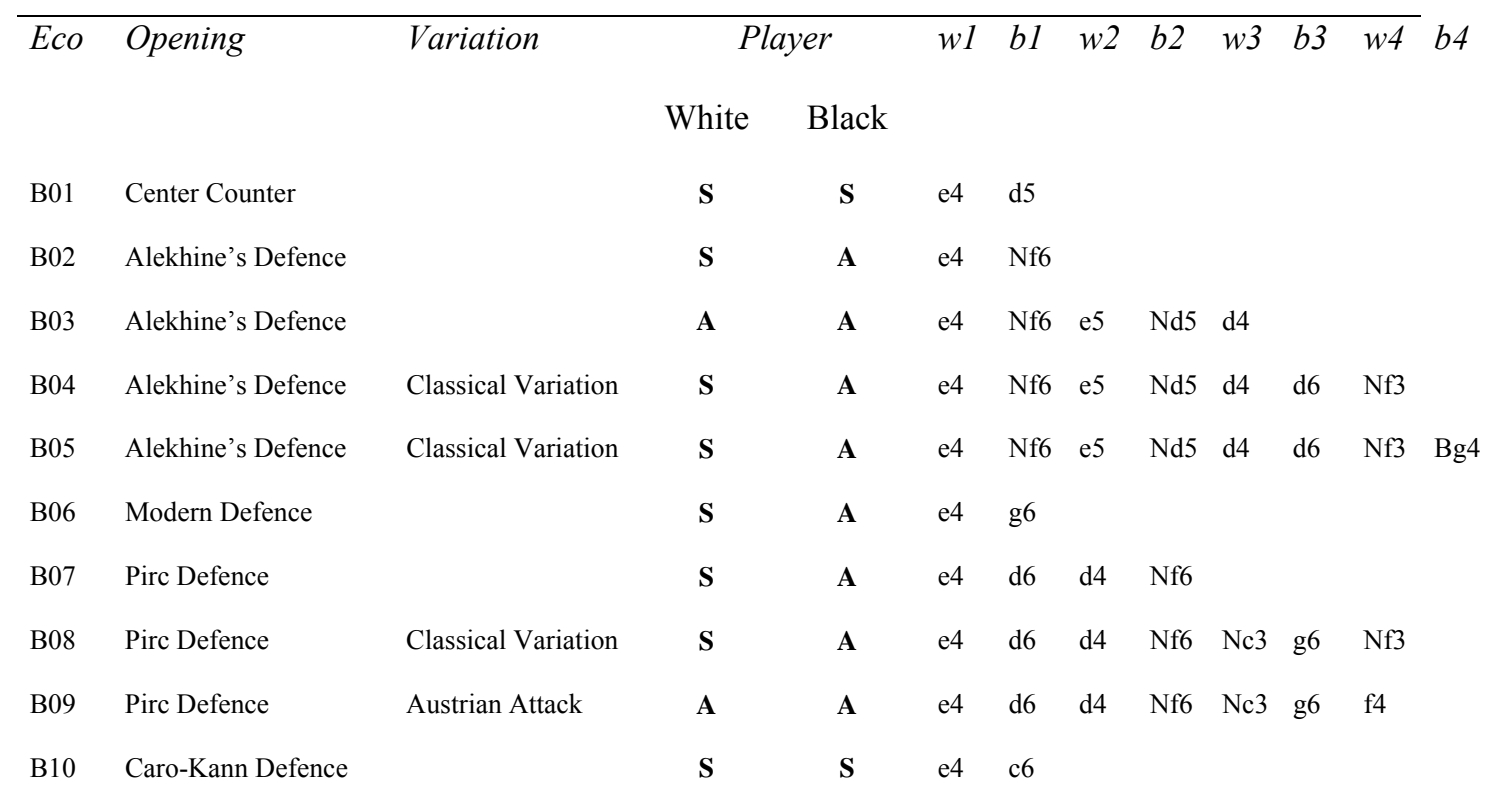

Note: w1: first move white; b2: second move black; etc. e4, d5, etc. denoting chessboard coordinates, while $\mathrm{N}$ and B denote knight and bishop, respectively.

Summary statistics on the classification of openings are shown in Table A.2. For example, an opening on the part of a white player is considered solid in $50 \%$ of all the 499 openings classified.

Table A. 2

\begin{tabular}{lccc}
\hline & Obs & Mean values & Standard deviations \\
\hline Solid OR, playing White & 499 & .501 & $(.501)$ \\
Solid OR, playing Black & 499 & .405 & $(.491)$ \\
Aggressive OR, playing White & 499 & .251 & $(.434)$ \\
Aggressive OR, playing Black & 499 & .297 & $(.457)$ \\
\hline
\end{tabular}

\section{The Elo Rating System}

The following section is to some extent drawn from "Arpad Elo and the Elo Rating System" by Daniel Ross. $\quad$ http://www.chessbase.com/newsdetail.asp?newsid=4326 The description aims to show how winning probabilities are calculated and how Elo rates of chess players are subsequently updated. 
In the late 1950s, Arpad Elo, physicist and himself a devoted chess player, introduced a new system of classifying the strength of chess players. By observing results from chess tournaments, he noted that the distribution of individual performances in chess resembled a normal distribution. On the basis of his observations, he introduced a point scale, where he determined the standard deviation to be 200 . The distribution relates to the difference in ability between two players. Defining $\mu$ as the difference in Elo strength between two players, this gives us the following probability density function (pdf), i.e. the marginal probability of winning:

$$
f(x)=\frac{1}{\sigma^{\prime} \sqrt{2 \pi}} e^{\frac{-(\mu)^{2}}{2 \sigma^{\prime 2}}}
$$

As there are two participants, each of them having an assumed performance deviation of 200 Elo points, the standard deviation used in (1) can be rewritten as follows:

$$
\sigma^{\prime}=\sqrt{\sigma_{1}^{2}+\sigma_{2}^{2}}=\sqrt{2 \sigma^{2}}=\sigma \sqrt{2=} 200 \sqrt{2}
$$

The cumulative distribution function of the pdf in (1) provides the expected probability of winning and is shown in (3), and Figure A.1.

$$
\int \frac{1}{\sigma^{\prime} \sqrt{2 \pi}} e^{\frac{-(\mu)^{2}}{2 \sigma^{\prime 2}}} d \mu=\frac{1}{400 \sqrt{\pi}} \int e^{\frac{-(\mu)^{2}}{400^{2}}} d \mu
$$

Figure A.1 about here

The two horizontal lines identify the probability of winning when the difference in Elo is 0 and 200, respectively. Consequently, the probability is 76 [24] percent if one player has 200 Elo points more [less] than his/her opponent. Where two players are equally strong (i.e. an Elo difference equal to zero), the most likely outcome is a draw. 


\section{Elo ratings: A sequential estimate of strength}

The probability of winning as shown in equation (3) is used to update a player's Elo rating. The algorithm for doing this reads as follows:

$$
\text { Elo_new }=\text { Elo_old }+(\text { Score }- \text { Prob }(\text { winning }))^{*} k
$$

Here Elo_old is the Elo rating before the game starts, while Elo_new is the updated rating. The Score indicates the actual outcome of a game, where a win [loss] is valued as 1 [0], and a draw counts as .5 point. The coefficient $k$ is a weighting factor that determines how much the outcome of a game counts for a player's Elo rating. It is determined by the number of games played, i.e. the less experienced a player is, the higher the $k$.

In some of our estimations a variable denoted "Elo points at stake" is included as a covariate. It is determined by setting the Score in (4) equal to one, and by determining $k$ as follows:

$$
k=\left\{\begin{array}{ccc}
130-E l o_{-} \text {old } / 20 & \text { if } \quad \text { Elo_old } & \exists[2000 ; 2400) \\
10 & & \\
\geq 2400
\end{array}\right.
$$


TABLE 1

Mean values at game level

Panel A.

\begin{tabular}{lcccccc}
\hline & \multicolumn{2}{c}{ All } & \multicolumn{2}{c}{ Men } & \multicolumn{2}{c}{ Women } \\
Variable & Mean & Std. Dev. & Mean & Std. Dev. & Mean & Std. Dev. \\
Solid OR & .471 & $(.499)$ & .472 & $(.499)$ & .462 & $(.499)$ \\
Aggressive OR & .203 & $(.402)$ & .202 & $(.402)$ & .206 & $(.404)$ \\
Elo score & 2339.230 & $(167.427)$ & 2348.023 & $(167.103)$ & 2242.834 & $(138.137)$ \\
Age & 32.809 & $(13.499)$ & 33.532 & $(13.565)$ & 24.887 & $(9.701)$ \\
Aged max 20 in \% & .212 & $(.409)$ & .192 & $(.393)$ & .435 & $(.496)$ \\
Number of games & & & & & & \\
played per year & 33.959 & $(29.624)$ & 34.017 & $(30.135)$ & 33.314 & $(23.288)$ \\
& & & & & & \\
North America & .027 & $(.162)$ & .028 & $(.164)$ & .018 & $(.133)$ \\
Latin America & .036 & $(.187)$ & .038 & $(.191)$ & .020 & $(.141)$ \\
Nordic countries & .048 & $(.213)$ & .050 & $(.218)$ & .025 & $(.155)$ \\
Western Europe* & .398 & $(.489)$ & .412 & $(.492)$ & .241 & $(.428)$ \\
Eastern Europe & .271 & $(.445)$ & .266 & $(.442)$ & .323 & $(.468)$ \\
fr Soviet Union & .175 & $(.380)$ & .163 & $(.370)$ & .305 & $(.460)$ \\
N Africa /Mid Eat & .011 & $(.104)$ & .011 & $(.103)$ & .012 & $(.110)$ \\
East Asia & .027 & $(.162)$ & .024 & $(.154)$ & .055 & $(.227)$ \\
Africa & .001 & $(.023)$ & .001 & $(.023)$ & .001 & $(.029)$
\end{tabular}

Panel B.

\begin{tabular}{lllllllll}
\hline & & \multicolumn{9}{c}{ Mean values over regions } \\
& North & Latin & Nordic & West & East & fr. Sov. & N. Africa/ & East \\
& America & America & countries & Europe & Europe & Union & Mid.East & Asia \\
Elo score & 2389.3 & 2364.5 & 2322.6 & 2291.6 & 2338.9 & 2433.0 & 2365.3 & 2373.9 \\
fem share & .056 & .046 & .043 & .051 & .100 & .146 & .094 & .170 \\
Age & 34.1 & 32.6 & 32.9 & 34.8 & 32.7 & 29.6 & 27.5 & 26.2 \\
\hline
\end{tabular}

Note: All mean values calculated on figures according to the period 1997 to 2007 . $*$ Net of Nordic countries. 


\section{TABLE 2}

OLS estimations regarding gender differences in playing opening strategies.

\section{Dependent variable:}

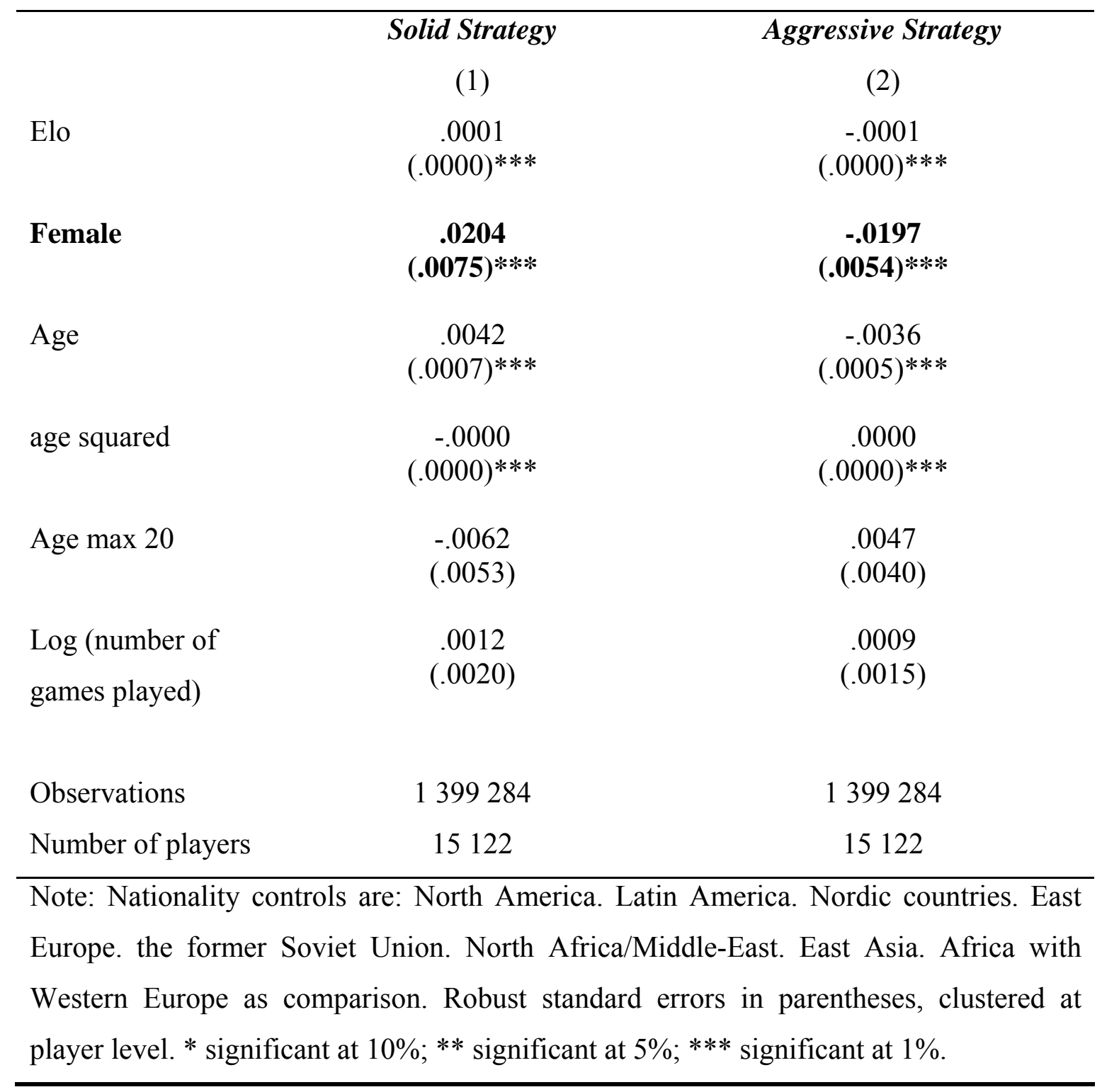




\section{TABLE 3}

OLS estimations regarding the impact of playing against a woman on the choice of opening. MEN.

\begin{tabular}{|c|c|c|c|c|c|}
\hline \multicolumn{6}{|c|}{ Dependent variable: Choosing solid opening strategies, yes or no } \\
\hline & \multirow[t]{3}{*}{ (1) } & \multirow[t]{3}{*}{ (2) } & \multirow[t]{3}{*}{ (3) } & (4) & $(5)$ \\
\hline & & & & Elo $>$ than & Elo $<$ than \\
\hline & & & & opponent & opponent \\
\hline \multirow[t]{2}{*}{ Female opponent } & -.0133 & -.0136 & -.0099 & -.0084 & -.0053 \\
\hline & $(.0037) * * *$ & $(.0025)^{* * *}$ & $(.0023) * * *$ & $(.0029) * * *$ & $(.0041)$ \\
\hline Individual fixed & No & Yes & Yes & Yes & Yes \\
\hline \multicolumn{6}{|l|}{ effects } \\
\hline Indicator opponent & No & No & Yes & Yes & Yes \\
\hline \multicolumn{6}{|l|}{ playing Solid } \\
\hline Including measure & No & No & Yes & Yes & Yes \\
\hline \multicolumn{6}{|l|}{ Elo points at stake } \\
\hline Observations & 1282315 & 1282315 & 1282315 & 678652 & 599418 \\
\hline Number of players & 13985 & 13985 & 13985 & 13755 & 13978 \\
\hline \multicolumn{6}{|c|}{$\begin{array}{l}\text { Note: Robust standard errors in parentheses, clustered at player level. Other control variables } \\
\text { are Elo. age. age squared. Age_max_20. Log (number of games played). } \\
* \text { significant at } 10 \% ; * * \text { significant at } 5 \% ; * * * \text { significant at } 1 \%\end{array}$} \\
\hline
\end{tabular}


TABLE 4

OLS estimations regarding the impact of playing against a woman on the choice of opening. WOMEN.

\begin{tabular}{|c|c|c|c|c|c|}
\hline \multicolumn{6}{|c|}{ Dependent variable: Choosing solid opening strategies, yes or no } \\
\hline & (1) & (2) & (3) & (4) & $(5)$ \\
\hline & & & & Elo $>$ than & Elo $<$ than \\
\hline & & & & opponent & opponent \\
\hline \multirow[t]{2}{*}{ Female opponent } & .0010 & .0010 & -.0006 & .0034 & -.0027 \\
\hline & $(.0052)$ & $(.0032)$ & $(.0031)$ & $(.0044)$ & $(.0042)$ \\
\hline Individual fixed effects & No & Yes & Yes & Yes & Yes \\
\hline Indicator opponent & No & No & Yes & Yes & Yes \\
\hline \multicolumn{6}{|l|}{ playing Solid } \\
\hline Elo points at stake & No & No & Yes & Yes & Yes \\
\hline Observations & 116969 & 116969 & 116969 & 53864 & 62768 \\
\hline Number of players & 1137 & 1137 & 1137 & 1087 & 1137 \\
\hline \multicolumn{6}{|c|}{ Note: Robust standard errors in parentheses, clustered at player level. Other control variables at } \\
\hline \multicolumn{6}{|c|}{ Elo. age. age squared. Age_max_20.Log (number of games played). } \\
\hline \multicolumn{6}{|c|}{$*$ significant at $10 \% ; * *$ significant at $5 \% ; * * *$ significant at $1 \%$} \\
\hline
\end{tabular}




\section{TABLE 5}

OLS estimations regarding the impact of playing against a woman on the choice of opening. MEN.

\begin{tabular}{|c|c|c|c|c|c|}
\hline \multicolumn{6}{|c|}{ Dependent variable: Choosing aggressive opening strategies, yes or no } \\
\hline & \multirow[t]{2}{*}{ (1) } & \multirow[t]{2}{*}{ (2) } & \multirow[t]{2}{*}{ (3) } & (4) & $(5)$ \\
\hline & & & & Elo $>$ than & Elo $<$ than \\
\hline & & & & opponent & opponent \\
\hline \multirow[t]{2}{*}{ Female opponent } & .0013 & .0068 & .0077 & .0069 & .0080 \\
\hline & (.0028) & $(.0020)^{* * *}$ & $(.0020) * * *$ & $(.0024)^{* * *}$ & $(.0036)^{* *}$ \\
\hline Individual fixed effects & No & Yes & Yes & Yes & Yes \\
\hline Indicator opponent & No & No & Yes & Yes & Yes \\
\hline \multicolumn{6}{|l|}{ playing Aggressive } \\
\hline Elo points at stake & No & No & Yes & Yes & Yes \\
\hline Observations & 1282315 & 1282315 & 1282315 & 678652 & 599418 \\
\hline Number of players & 13985 & 13985 & 13985 & 13755 & 13978 \\
\hline \multicolumn{6}{|c|}{ Note: Robust standard errors in parentheses, clustered at player level. Other control variables are } \\
\hline \multicolumn{6}{|c|}{ Elo. age. age squared. Age_max_20.Log (number of games played). } \\
\hline \multicolumn{6}{|c|}{$*$ significant at $10 \% ; * *$ significant at $5 \% ; * * *$ significant at $1 \%$} \\
\hline
\end{tabular}


TABLE 6

OLS estimations regarding the impact of playing against a woman on the choice of opening. WOMEN.

Dependent variable: Choosing aggressive opening strategies, yes or no

(1)

(2)
(3)

(4)
(5)

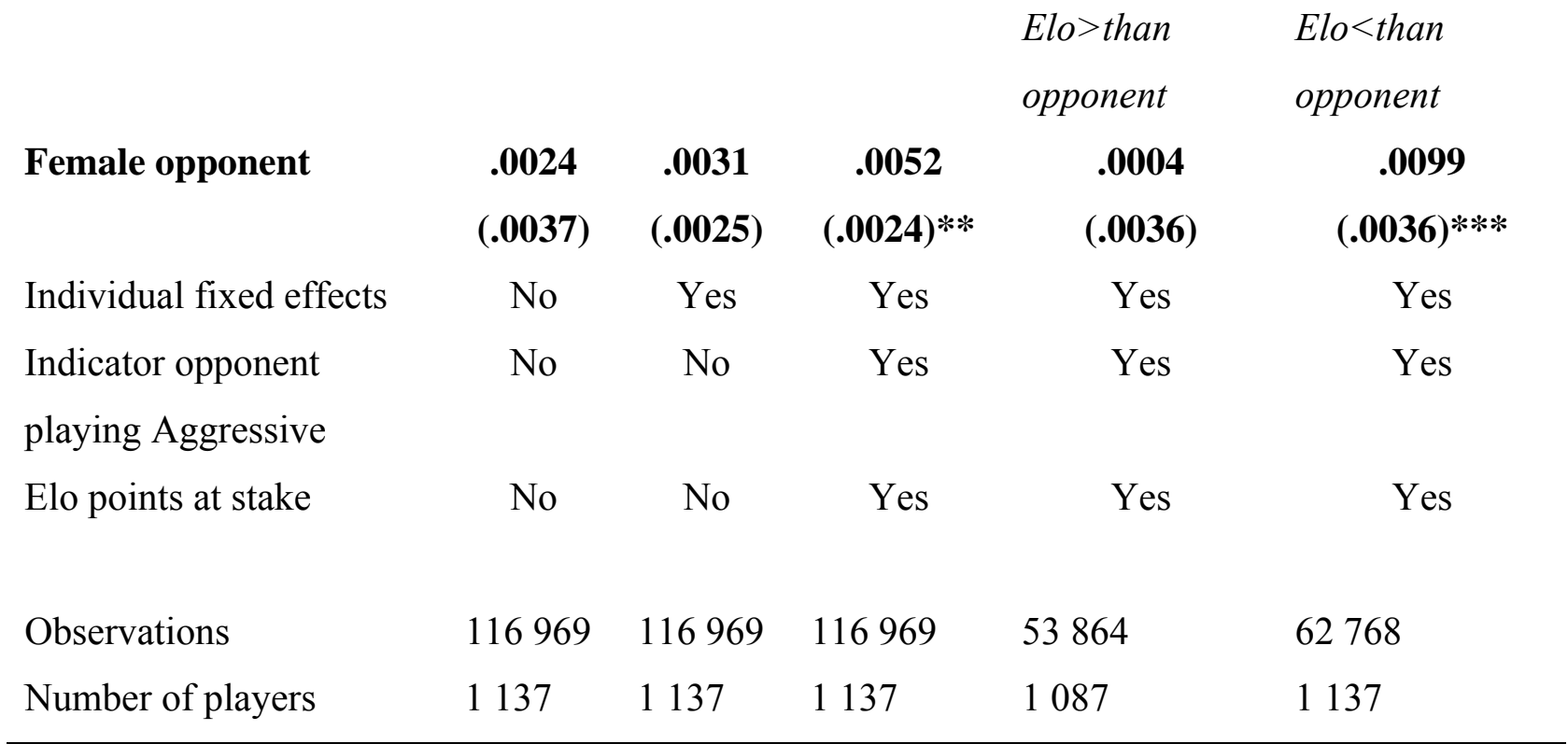

Note: Robust standard errors in parentheses, clustered at player level. Other control variables are Elo. age. age squared. Age_max_20. Log (number of games played).

* significant at $10 \%$; ** significant at $5 \%$; ** significant at $1 \%$ 


\section{TABLE 7}

OLS estimations regarding the probability of winning a game when playing against a woman and using a solid strategy. MEN.

\begin{tabular}{|c|c|c|c|c|c|}
\hline \multicolumn{6}{|c|}{ Dependent variable: Bivariate outcome of winning (1) or losing (0) a game } \\
\hline & \multirow[t]{2}{*}{$(1)$} & \multirow[t]{2}{*}{ (2) } & \multirow[t]{2}{*}{ (3) } & (4) & $(5)$ \\
\hline & & & & Elo $>$ than & Elo $<$ than \\
\hline & & & & opponent & opponent \\
\hline \multirow[t]{2}{*}{ Solid strategy } & .0140 & .0129 & .0156 & .0234 & .0182 \\
\hline & $(.0053) * * *$ & $(.0073)^{*}$ & $(.0069) * *$ & $(.0085) * * *$ & $(.0149)$ \\
\hline Individual fixed & No & Yes & Yes & Yes & Yes \\
\hline \multicolumn{6}{|l|}{ effects } \\
\hline Indicator opponent & No & No & Yes & Yes & Yes \\
\hline \multicolumn{6}{|l|}{ playing Solid } \\
\hline Elo points at stake & No & No & Yes & Yes & Yes \\
\hline Observations & 34011 & 34011 & 34011 & 22515 & 11423 \\
\hline Number of players & 8818 & 8818 & 8818 & 6717 & 4722 \\
\hline \multicolumn{6}{|c|}{ Note: Robust standard errors in parentheses, clustered at player level. Other control variables ar } \\
\hline \multicolumn{6}{|c|}{ Elo. age. age squared. Age_max_20.Log (number of games played). } \\
\hline \multicolumn{6}{|c|}{$*$ significant at $10 \% ; * *$ significant at $5 \% ; * * *$ significant at $1 \%$} \\
\hline
\end{tabular}




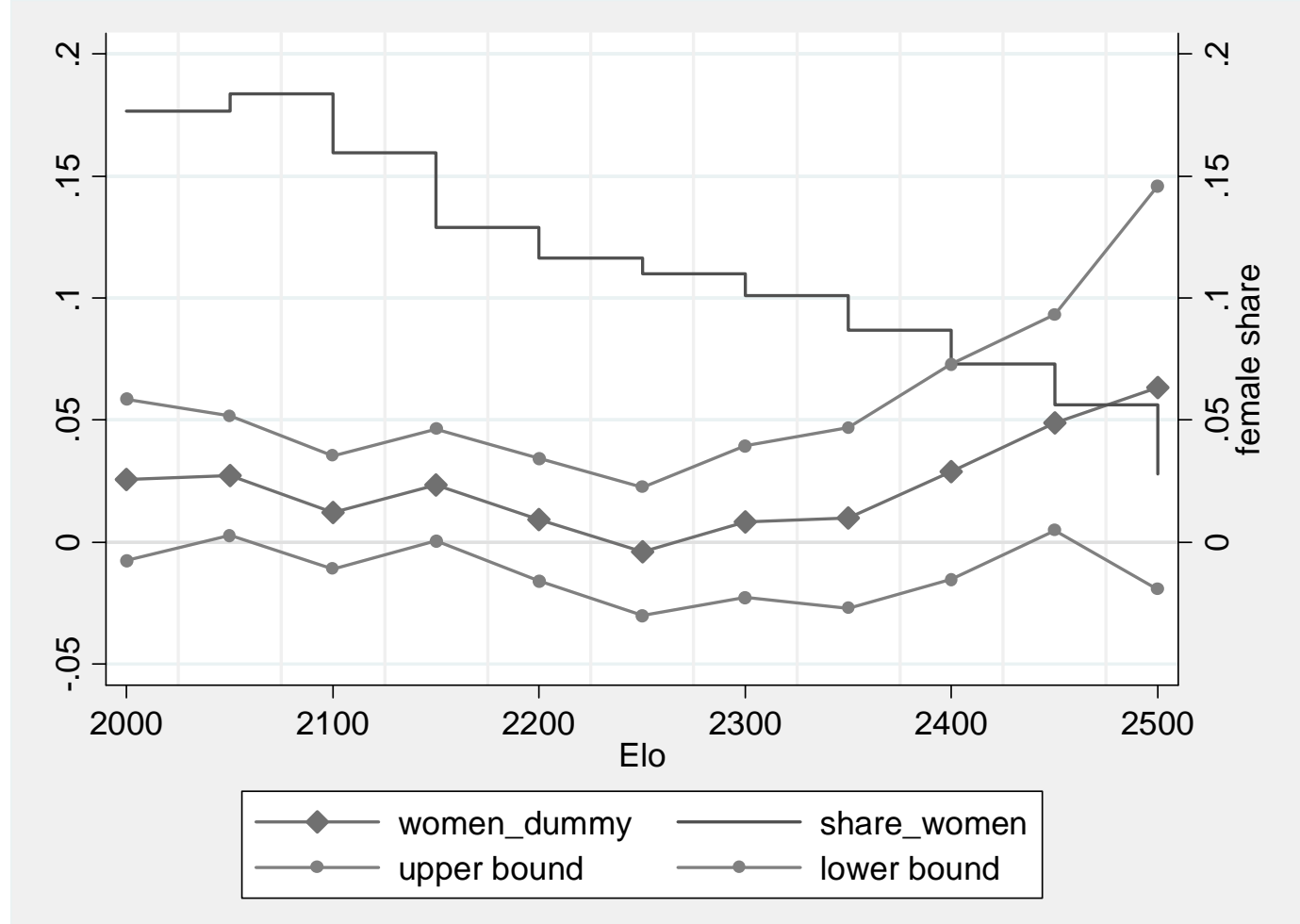

Fig.1. Coefficient for women dummy for Solid as dependent variable. Upper and lower bound indicating $95 \%$ confidence interval.

Notes: Results from regression estimations using a window of 50 Elo rating points, e.g. 2200+/-25. Standard errors clustered on individual level. Control variables included as in Table 2. 


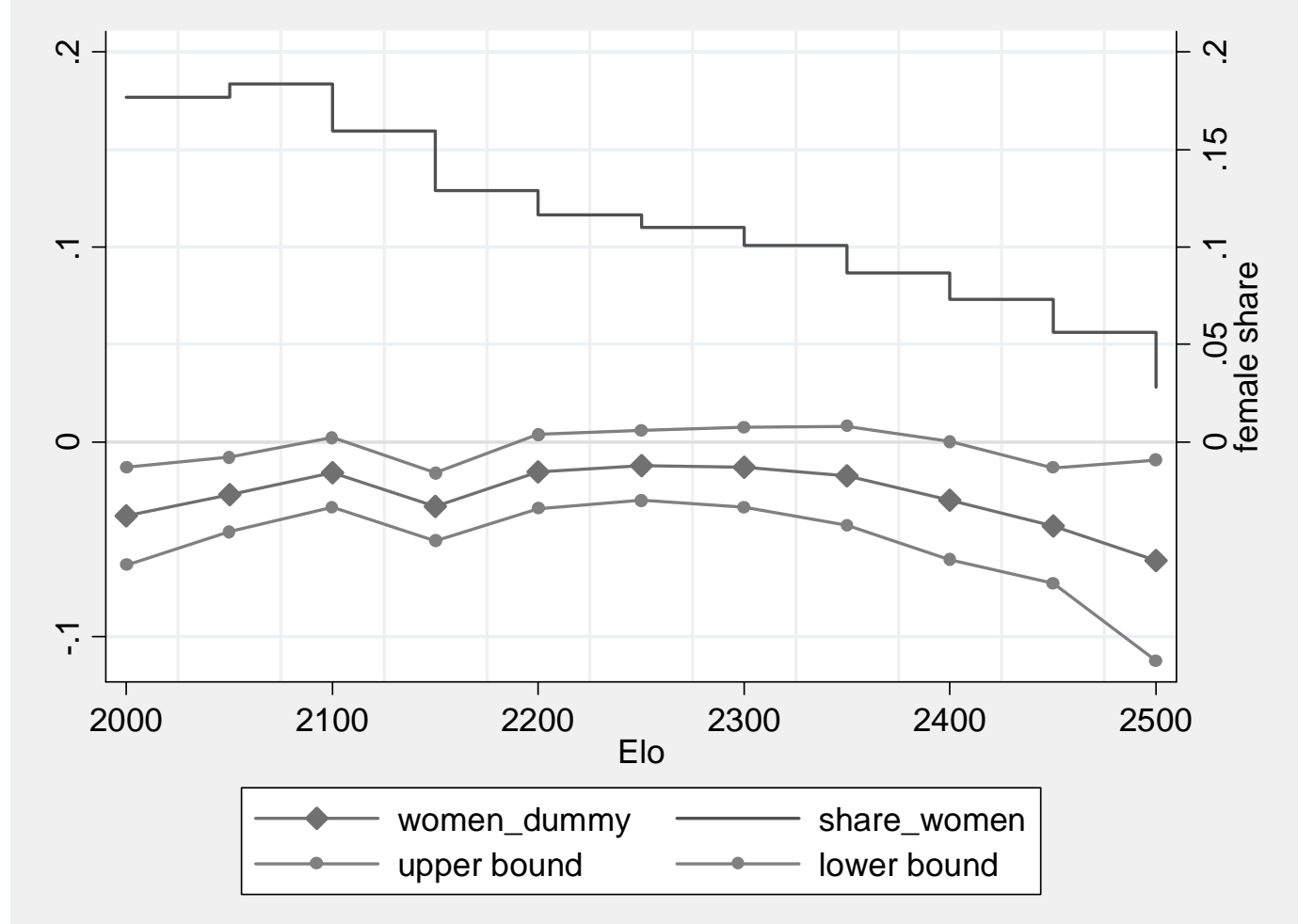

Fig.2. Coefficient for women dummy for Aggressive as dependent variable. Upper and lower bound indicating 95\% confidence interval.

Notes: Results from regression estimations using a window of 50 Elo rating points, e.g. 2200+/-25. Standard errors clustered on individual level. Control variables included as in Table 2. 


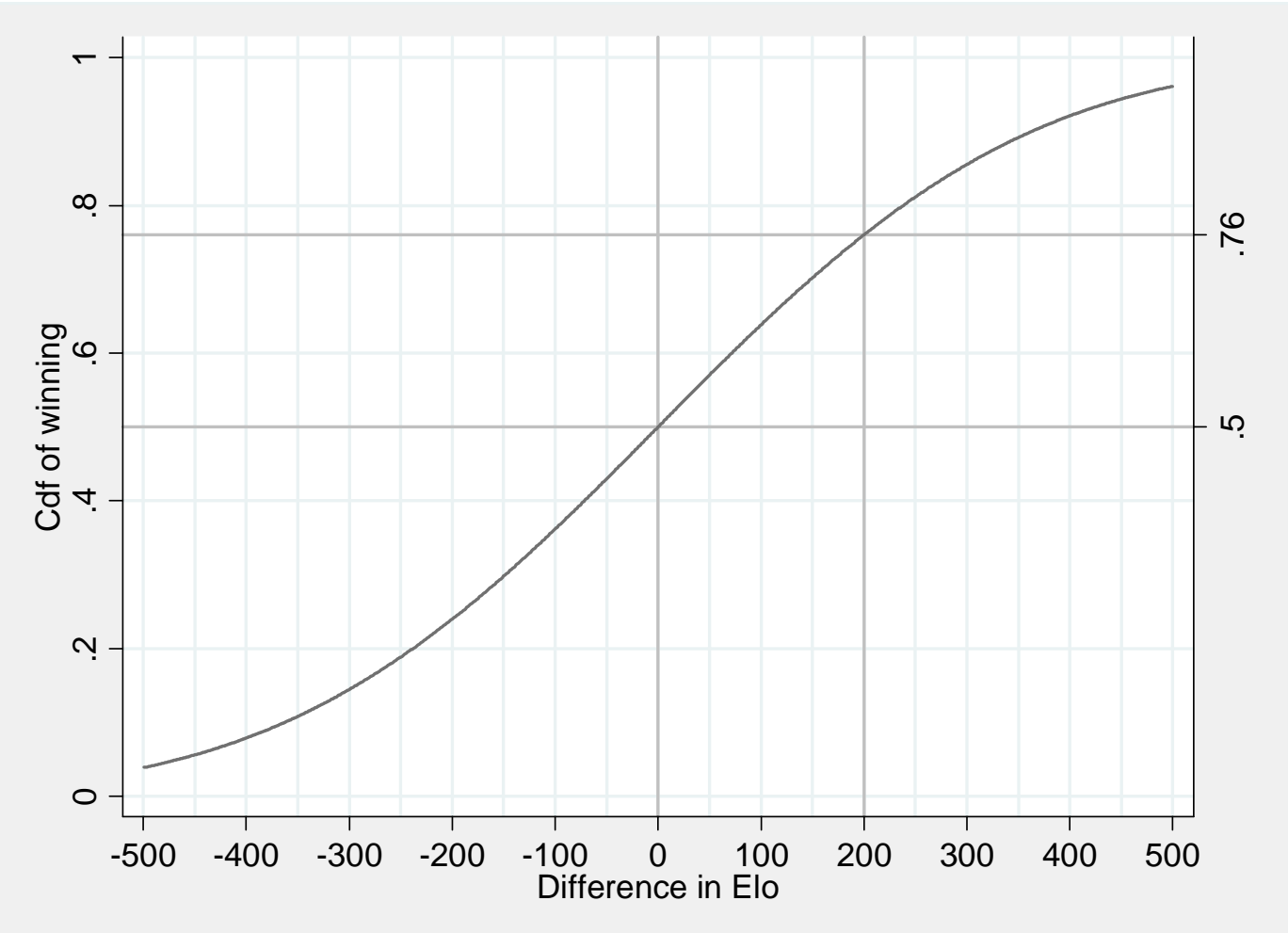

Fig.A.1. Cumulative probability of winning a chess game based on differences in Elo rating points between two players. 